\title{
Back to the Moon
}

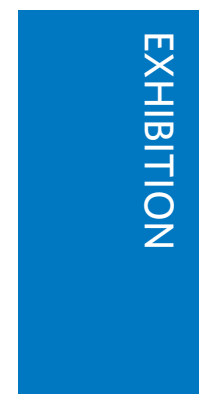

It has been 50 years since the first Moon landing and - despite the long time elapsed - the fascination inspired by that incredible achievement has not faded. People are as interested as ever to hear about Moon missions past and future. The Moon, the exhibition that runs until 5 January 2020 at the

National Maritime Museum in Greenwich, is the perfect place to get an impression of what our satellite has meant for humans throughout history, and to ponder our relationship with it today.

The exhibition is an ideal size to be examined in an hour or two, and uses a clever collection of disparate Moon-related objects from popular culture, science fiction and history to weave a fascinating story. Animations that explain the Moon's phases and eclipses stand next to ancient and contemporary Moon-inspired artwork in an engaging blend of science and culture.

Humans have always been mesmerized by the Moon, which has a special role in every culture. The exhibit does an excellent job of capturing this diversity by displaying Moon-related artefacts from different times and corners of the world.

So we meet Chinese Moon goddess Chang'e, who was banished to the Moon for drinking the elixir of life, and lives there with the rabbit Yutu. The Chinese see his silhouette on the surface of the Moon as he grinds ingredients with a pestle and mortar. In a poster from the early days of the Cultural Revolution, we see Chang'e and Yutu (who lend their names to Chinese lunar missions) welcoming young Chinese space travellers to the Moon.

A Moon mask used in ceremonial dances by the First Nations people of Canada sits next to a representation of the Hindu Moon god Chandra. Not far is a small Madonna, who is often associated with the Moon because they both symbolize purity, side by side with a statuette of the Egyptian Moon god Iah, who lost five days of moonlight in a game of dice with Toth. Toth, adding the extra days to the lunar calendar, created the solar calendar.

It's a fact lost on many that the first work of science fiction comes straight from

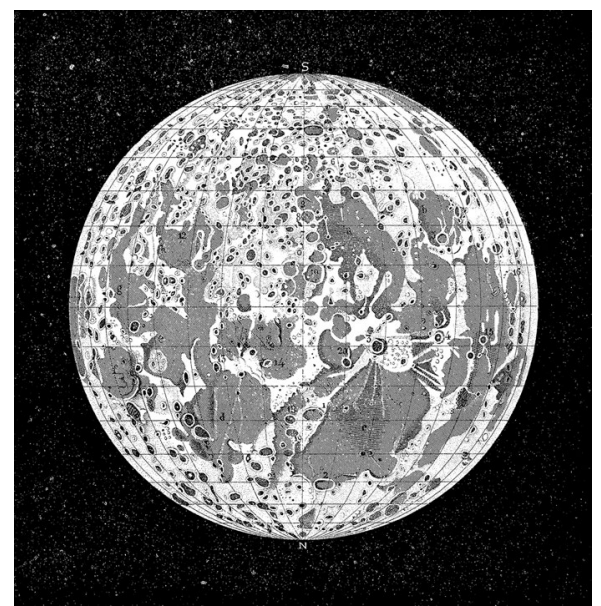

Credit: lilbusca / Getty

Roman times, and of course it features the Moon: in his A True Story (written in the second century $\mathrm{CE}$ ), Luciano imagines travellers who, taken to the Moon by a whirlwind, get caught up in a war between the king of the Moon and the king of the Sun over the dominion of the Morning Star.

Move a few centuries forward and we get to a beautifully illustrated version of the sixteenth-century tale of chivalry Orlando Furioso by Ariosto, in which the Moon is the place where all that has been lost on Earth can be found, including Orlando's wits, which a fellow knight had to recover. The exhibit then moves on to the classic science fiction masterpieces that shaped the imagination of generations of children (and not only) with works by H. G. Wells and Jules Verne, who first dreamed up scientifically credible trips to the Moon.

A copy of Tintin's lunar adventures, which predate the actual lunar landing by only 16 years, is also on display. After the (real) landing, Hergé sent Neil Armstrong a congratulatory cartoon, showing Tintin greeting the astronauts as they come out of the lander, looking understandably puzzled at finding someone out there.

The exhibit contains items and recordings from several lunar missions, and helpful timelines tracing the progress of the American and Soviet lunar programmes. It follows in some detail the Apollo missions leading up to the landing, which started in 1967 with the tragic death of three astronauts during a launch test of Apollo 1, and continued with un-crewed and then crewed flights in Earth orbit (until Apollo 7), the crewed mission in Moon orbit that captured the iconic 'Earthrise' picture (Apollo 8) and two missions that tested systems and mapped the Moon's surface (Apollo 9 and 10) in preparation for the Apollo 11 landing.

The reconnaissance pictures, however, did not fully capture the roughness of the surface, and famously, when the moment to land came, Armstrong had to change the touchdown location at the last minute. Apollo 17 in 1972 was the last Apollo mission, and the last time a human set foot on the Moon.

But Moon missions are not a thing of the past. In 1990, Japan launched the first mission since the Soviet Luna 24 in 1976. China performed the first soft Moon landing after the Apollo ones in 2013. Commercial Moon landings are being planned, and proposals to send people to the Moon again have recently been in the news.

A scale model shows that planning for a scientific village at the Moon's south pole, which might hold water ice and perhaps sustain life, is underway: the European Space Agency is teaming up with architects Foster + Partners to investigate how feasible this is. Buildings could be made of regolith, lunar soil, hardened by $3 \mathrm{D}$ printing and assembled by robots.

With its peaceful atmosphere, slowmoving projected images from the Moon orbiter and classical music playing in the background (when it's not footage from Apollo 11), The Moon immerses visitors in a contemplative mood, making them walk away in the realization that the Moon means more to each of us than we previously thought.

The Moon exhibition is being held at the National Maritime Museum in Greenwich, UK from July 2019 to January 2020.

Reviewed by Giulia Pacchioni Senior Editor, Nature Reviews Materials. e-mail:Giulia.Pacchioni@nature.com

Published online: 2 December 2019 https://doi.org/10.1038/s41567-019-0738-7 